\title{
Global Hawk dropsonde observations of the Arctic atmosphere obtained during the Winter Storms and Pacific Atmospheric Rivers (WISPAR) field campaign
}

\author{
J. M. Intrieri ${ }^{1}$, G. de Boer ${ }^{1,2}$, M. D. Shupe ${ }^{1,2}$, J. R. Spackman ${ }^{1,3}$, J. Wang ${ }^{4,6}$, P. J. Neiman ${ }^{1}$, G. A. Wick ${ }^{1}$, T. F. Hock ${ }^{4}$, \\ and R. E. Hood ${ }^{5}$ \\ ${ }^{1}$ NOAA, Earth System Research Laboratory, 325 Broadway, Boulder, CO 80305, USA \\ ${ }^{2}$ Cooperative Institute for Research in the Environmental Sciences, University of Colorado at Boulder, Box 216 UCB, \\ Boulder, CO 80309, USA \\ ${ }^{3}$ Science and Technology Corporation, Boulder, CO 80305, USA \\ ${ }^{4}$ National Center for Atmospheric Research, 1850 Table Mesa Dr., Boulder, CO 80305, USA \\ ${ }^{5}$ NOAA, Unmanned Aircraft Systems Program, 1200 East West Highway, Silver Spring, MD 20910, USA \\ ${ }^{6}$ University at Albany, SUNY, Department of Atmospheric \& Environmental Sciences, Albany, NY 12222, USA
}

Correspondence to: J. M. Intrieri (janet.intrieri@noaa.gov)

Received: 20 February 2014 - Published in Atmos. Meas. Tech. Discuss.: 23 April 2014

Revised: 15 September 2014 - Accepted: 20 October 2014 - Published: 25 November 2014

\begin{abstract}
In February and March of 2011, the Global Hawk unmanned aircraft system (UAS) was deployed over the Pacific Ocean and the Arctic during the Winter Storms and Pacific Atmospheric Rivers (WISPAR) field campaign. The WISPAR science missions were designed to (1) improve our understanding of Pacific weather systems and the polar atmosphere; (2) evaluate operational use of unmanned aircraft for investigating these atmospheric events; and (3) demonstrate operational and research applications of a UAS dropsonde system at high latitudes. Dropsondes deployed from the Global Hawk successfully obtained high-resolution profiles of temperature, pressure, humidity, and wind information between the stratosphere and surface. The $35 \mathrm{~m}$ wingspan Global Hawk, which can soar for $\sim 31 \mathrm{~h}$ at altitudes up to $\sim 20 \mathrm{~km}$, was remotely operated from NASA's Dryden Flight Research Center at Edwards Air Force Base (AFB) in California.

During the $25 \mathrm{~h}$ polar flight on 9-10 March 2011, the Global Hawk released 35 sondes between the North Slope of Alaska and $85^{\circ} \mathrm{N}$ latitude, marking the first UAS Arctic dropsonde mission of its kind. The polar flight transected an unusually cold polar vortex, notable for an associated record-level Arctic ozone loss, and documented polar boundary layer variations over a sizable ocean-ice lead feature.
\end{abstract}

Comparison of dropsonde observations with atmospheric reanalyses reveal that, for this day, large-scale structures such as the polar vortex and air masses are captured by the reanalyses, while smaller-scale features, including low-level jets and inversion depths, are mischaracterized. The successful Arctic dropsonde deployment demonstrates the capability of the Global Hawk to conduct operations in harsh, remote regions. The limited comparison with other measurements and reanalyses highlights the potential value of Arctic atmospheric dropsonde observations where routine in situ measurements are practically nonexistent.

\section{Introduction}

Recently observed changes in the Arctic environment, most notably the diminishing summer sea ice and the expansion of open-water regions (Stroeve et al., 2012), are facilitating increased access to high-latitude ocean areas. This increased activity elevates the need for observations and information to support ecosystem, environmental, social, and economic decision-making. The most recent projections show that the Arctic Ocean could be nearly ice-free in summer near mid-century (Wang and Overland, 2012), affecting 
marinetransportation, regional weather, fisheries and ecosystem structures, energy and natural resource management, and coastal communities. In addition to sea ice loss being a major driver of significant Arctic system-wide changes, there exists the potential for impacts on midlatitude weather systems and long-term climate (e.g., Cohen et al., 2014). Understanding the changing Arctic system and its impacts on weather and climate requires routine observation of the Arctic atmosphere, ocean, and sea ice; process-level understanding and improved coupled atmosphere-ice-ocean forecast models; and the development of services and information products needed by stakeholders and decision-makers.

The Arctic environment is remote, expansive, challenging to operate in, lacking in atmospheric observations, and changing regionally at a rapid pace. For these reasons, the use of unmanned aircraft systems (UASs) can be of great benefit toward improving our understanding of Arctic weather and climate. In particular, the range, altitude, and endurance capabilities of larger UASs can fill a critical gap in the Arctic regions where profiles of the atmospheric state are extremely limited. Ultimately, routine UAS observations can result in improvements in understanding and predicting key interactions between the ocean, atmosphere, and sea ice systems by (1) providing evaluation data sets for atmospheric reanalysis products; (2) validating model simulation results and satellite data products; and (3) obtaining measurements that can be assimilated into numerical weather prediction models to improve polar weather, marine, and sea ice forecasts.

In this paper, we present measurements obtained in the Arctic during the Winter Storms and Pacific Atmospheric Rivers (WISPAR) field campaign. In February and March of 2011, the Global Hawk (GH) UAS was deployed over the Pacific Ocean and the Arctic in science missions that were designed to (1) improve our scientific understanding of Pacific weather systems and the polar atmosphere; (2) evaluate the operational use of unmanned aircraft for investigating atmospheric events over remote data-sparse regions; and (3) demonstrate and test the newly developed Global Hawk dropsonde system. The Global Hawk is classified as a highaltitude, long-endurance (HALE) UAS platform which distinguishes it from other UASs that are smaller, fly at lower altitudes, carry less weight in payload, and have vastly limited ranges in comparison. Here, we present details of the WISPAR Arctic mission (one of three Global Hawk flights obtained during WISPAR), which was the first successful high-altitude and high-latitude UAS mission with dropsonde capability. This high-Arctic flight allows us to provide examples of the benefits of UAS dropsonde measurements for evaluating concurrent ground-based observations, comparing results of reanalyses data sets, and understanding the Arctic atmospheric features from the polar vortex to boundary layer structures.

\section{The Global Hawk UAS and dropsonde measurement system}

The National Oceanic and Atmospheric Administration (NOAA) is utilizing a variety of UAS, ranging from small hand-launched systems to the high-altitude, long-endurance Global Hawk, to support NOAA research and future operational data collection (MacDonald, 2005). In the winter of 2011, the Global Hawk was deployed as part of WISPAR. WISPAR was conducted through a collaborative tri-agency effort involving NOAA, NASA, and the National Center for Atmospheric Research (NCAR). The main objective of the NOAA-led WISPAR campaign was to demonstrate the operational and research applications of a UAS in remote regions and to test a newly developed dropsonde system. The WISPAR science missions targeted three areas of interest using the Global Hawk: atmospheric rivers (Ralph and Dettinger, 2011; Neiman et al., 2014), Pacific winter storms, and the Arctic atmosphere.

The Global Hawk represents a tremendous asset in the collection of atmospheric data. With an ability to cruise at altitudes up to $\sim 20 \mathrm{~km}$, operate for over $31 \mathrm{~h}$ at a time, and cover distances over $\sim 18500 \mathrm{~km}$ (10 000 nautical miles), the Global Hawk can cover extensive ground in a single flight (Naftel, 2009). For WISPAR, the $35 \mathrm{~m}$ wingspan Global Hawk was remotely operated from its base at NASA Dryden Flight Research Center (DFRC) on the Edwards Air Force Base in southern California. The Global Hawk Operations Center (GHOC) at DFRC consists of three areas, including a flight operations room, payload operations room, and a support equipment room. For typical flights the flight operations room is manned by a pilot, flight support engineer, mission director, GHOC operator, and a range safety operator. Communications between DFRC and the Global Hawk are carried out using a primary and redundant Iridium satellite link. Standard in situ observations acquired by the GH include air speed velocity, pressure, and temperature, as well as platform system parameters, including skin temperature and fuel temperature, and a high-definition (HD) camera for forward-looking imagery to provide situational awareness for the plane and scientific goals. The Global Hawk flight track for the Arctic mission was confined to a wedge defined by US borders and with a turnaround limit of $85^{\circ} \mathrm{N}$. The flight plan was filed with GH mission operations 1 week in advance, with a $24 \mathrm{~h}$ window allowed for any modifications. During WISPAR, no dropsondes were deployed over land areas.

The WISPAR flights provided a unique testing opportunity for an innovative dropsonde system designed specifically for use with the Global Hawk through a collaborative effort between the NCAR Earth Observing Laboratory (EOL) and the NOAA Unmanned Aircraft Systems Program. This dropsonde system allows the Global Hawk to dispense up to 88 dropsondes per flight. The Global Hawk sondes, referred to as "mini-dropsondes", are smaller and half the weight of the 


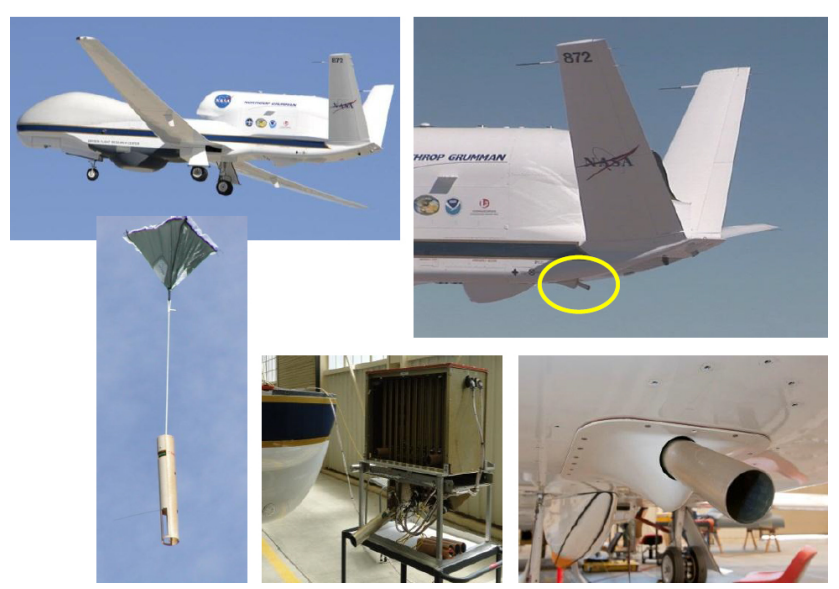

Figure 1. (Clockwise from top left) Global Hawk; close-up of Global Hawk with dropsonde eject tube, circled in yellow (photo courtesy of NASA); close-up of dropsonde launch tube (photo courtesy of NASA); dropsonde dispenser and launch assembly; dropsonde with parachute.

standard dropsondes (Vaisala RD9) deployed from manned aircraft (Hock and Franklin, 1999) but use the same sensor module for temperature, pressure, and humidity and the same type of GPS receiver for winds. The mini-dropsonde provides measurements of pressure, temperature, and relative humidity $(\mathrm{RH})$ profiles at $2 \mathrm{~Hz}$ (vertical resolution $\sim 30-5 \mathrm{~m}$ ) and wind speed and direction at $4 \mathrm{~Hz}$ resolution $(\sim 15-3 \mathrm{~m})$ from the launch altitude to the surface. The sondes have a fall rate of between $\sim 30 \mathrm{~m} \mathrm{~s}^{-1}$ at $15 \mathrm{~km}$ and $\sim 10 \mathrm{~m} \mathrm{~s}^{-1}$ in the boundary layer as it approaches the surface. The total weight of the sonde is $0.17 \mathrm{~kg}$, and the sensors, circuit board, and battery are housed in a cardboard tube that is $4.5 \mathrm{~cm}$ in diameter and $30.5 \mathrm{~cm}$ long. The dropsondes are deployed with a square-cone parachute, also smaller in size than its manned counterpart and designed to provide a stable descent, from an automated launching system in the aft of the aircraft (Fig. 1).

The sondes continuously measure the atmosphere from the release altitude to the surface. In situ data collected from the sonde sensors are transmitted back in real time to an onboard aircraft data system via radio link and then transmitted to the ground-control station via satellite communications link. The data system installed on the aircraft (closely resembling that employed on manned aircraft; Hock and Franklin, 1999) can process up to eight sondes simultaneously, allowing for closely spaced dropsonde deployment. Individual sondes can be deployed with a time separation of $1 \mathrm{~min}$ or less, while for continuous operations from an altitude of $20 \mathrm{~km}$ where the fall time is $\sim 18 \mathrm{~min}$ the sondes can be released every $2.5 \mathrm{~min}$, corresponding to a spacing of $\sim 25 \mathrm{~km}$, given a cruising speed of $170 \mathrm{~m} \mathrm{~s}^{-1}$. This spacing could be reduced by cruising at a lower altitude. The dropsonde system allows for on-demand release of the sondes, triggered remotely by the ground-based team. All dropsonde measurements are quality-controlled using established post-processing methods (Wang et al., 2010).

The mini-dropsonde uses the same pressure-temperature-humidity sensor module as is used in the Vaisala RS92 radiosonde (Vaisala, 2012), and the accuracy of this module is high and well documented (e.g., Nash et al., 2011). The dropsonde temperature measurement has an accuracy of 0.3 and $0.6^{\circ} \mathrm{C}$ from the surface to $100 \mathrm{hPa}$ and from 100 to $10 \mathrm{hPa}$, respectively (Nash et al., 2011), and it is subject to a calibration bias of $\sim 0.15^{\circ} \mathrm{C}$ (Wang et al., 2013). Comprehensive and independent field and laboratory testing to assess the mini-dropsonde measurement performance continue to be conducted by NCAR. Comparisons in the field with an infrared (IR) interferometer have suggested that the mini-dropsonde hygrometer may have a dry bias in very dry conditions at high launch altitudes (G. Wick, personal communication, 2014). The hygrometer used on mini-dropsondes, not optimized for low-water-vapor environments, do not measure RHs below $1 \%$.

\section{Arctic dropsonde flight}

The Arctic WISPAR flight was successfully carried out on 9-10 March 2011. In addition to demonstrating the dropsonde system in the harsh polar environment, the $25 \mathrm{~h}$ flight twice transected an atmospheric river event west of California, as well as a winter storm system off the Canadian coast (Fig. 2). The Global Hawk WISPAR science team was responsible for flight planning, identifying scientific objectives, and determining dropsonde locations prior to the flight. During the flight, the science team was able to participate remotely to provide input on decisions regarding flight changes while virtually monitoring onboard sensors and real-time information from the dropsondes.

In total, 70 dropsondes were deployed, including 35 deployments over the Arctic Ocean north of Alaska's northern coast. For this specific flight, the Global Hawk completed a $6 \mathrm{~h}$ overnight tour of the western Arctic in a triangular flight pattern between the North Slope of Alaska and $85^{\circ} \mathrm{N}$ latitude (Fig. 3). Of the 35 sondes dropped over the Arctic Ocean, 27 are used in the current analysis. The remaining eight soundings returned no data due to initialization and communication problems associated with the extreme cold temperatures encountered during the flight. This communications issue has since been corrected and does not affect current sondes.

\section{Demonstration of capabilities}

During the Global Hawk Arctic mission, dropsonde data sampled a variety of interesting atmospheric phenomena. In this paper, we use this case study to provide examples of how routine Global Hawk operations may be used to further shed light on the infrequently sampled Arctic atmosphere. Here, we cover three distinct topics using the observations from the 


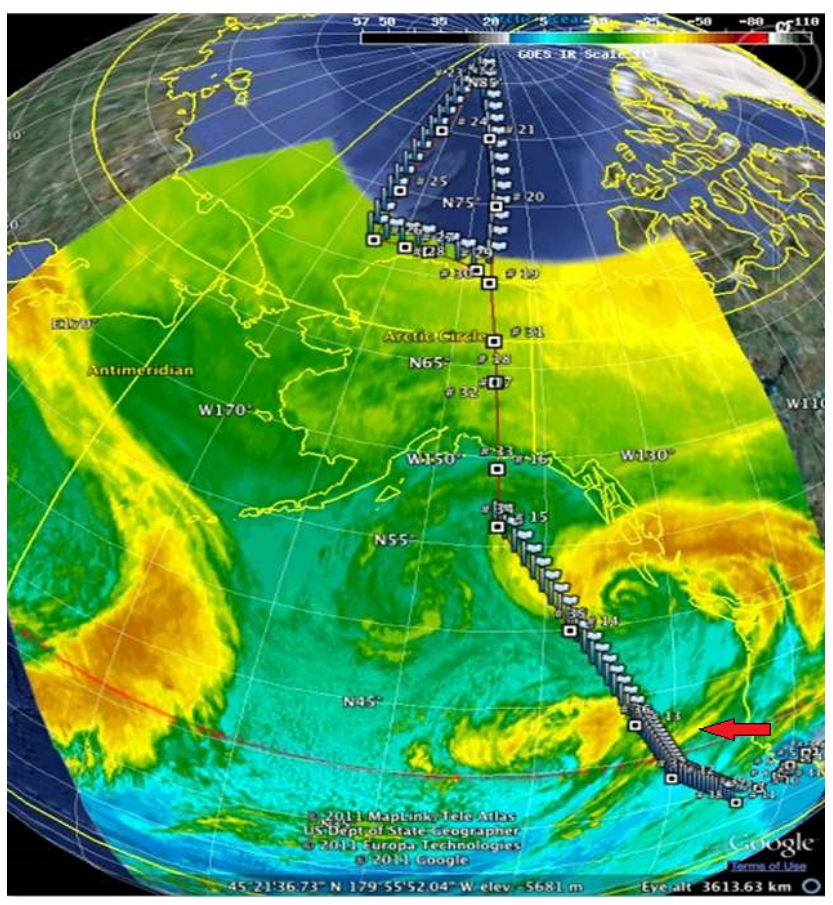

Figure 2. Global Hawk flight track overlaid on the GOES-11 (Geostationary Operational Environment Satellite) IR image for 9 March 2011. The atmospheric river (AR) feature is indicated by the red arrow.

9-10 March 2011 case study: the upper-troposphere-lowerstratosphere polar vortex structure; surface and boundary layer atmospheric features; and comparisons between dropsonde measurements and atmospheric reanalyses throughout the depth of the Arctic atmosphere.

\subsection{Sampling of the polar vortex}

The Arctic mission was noteworthy in part because of the especially cold stratospheric temperatures resulting from an anomalously deep and atypically long-lived polar vortex that persisted from December 2010 through to the end of March 2011. Extremely low stratospheric temperatures in the 2010-2011 winter were partially responsible for the record Arctic ozone loss observed that winter (Manney et al., 2011). Vertically resolved observations of the polar vortex are not often available due to the limited coverage of upper-air observations over the Arctic Ocean. The Global Hawk transect was able to characterize the structure of the lower portion of this unprecedented polar vortex.

Transecting the vortex provided challenges to the Global Hawk due to design-limit thresholds for fuel and airframe minimum temperatures. On the northbound leg, ambient temperatures decreased to $-76^{\circ} \mathrm{C}$ (within $2{ }^{\circ} \mathrm{C}$ of the critical skin temperature for the Global Hawk) at the polar vortex edge $\left(77^{\circ} \mathrm{N}\right)$. Real-time mission information from the dropsondes, onboard sensors, and polar vortex temperature

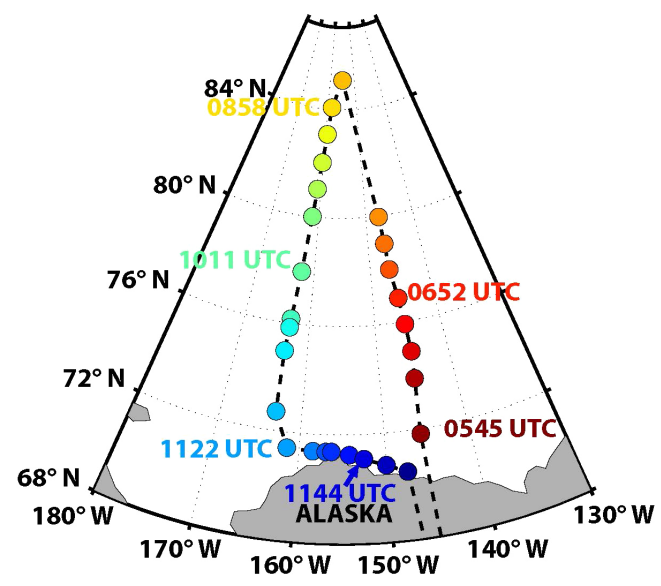

Figure 3. Global Hawk Arctic flight track showing Alaska coastline. The dropsonde locations on 10 March 2011 are indicated by colored circles, and times (UTC) associated with certain dropsondes are indicated using the corresponding color.

forecasts from NASA resulted in a decision to have the Global Hawk descend from 18.3 to $13.7 \mathrm{~km}$ in order to warm the aircraft while continuing on the planned flight track. After exiting the region of low stratospheric temperatures, the Global Hawk ascended back to $18.3 \mathrm{~km}$ and completed the mission as planned.

The wind speed and potential temperature cross sections in Fig. 4 (top panels) illustrate the flight altitude changes described above and the vertical structure of the vortex temperature and winds captured by these transects. While wind speeds were always weak near the sea ice surface, there was a dramatic decrease in wind speeds at $\sim 10 \mathrm{~km}$ from $45 \mathrm{~m} \mathrm{~s}^{-1}$ on the outside edge to $3 \mathrm{~m} \mathrm{~s}^{-1}$ within the vortex core $\left(\sim 84^{\circ} \mathrm{N}\right)$. The asymmetry in the wind speed and direction measurements indicate that the vortex center was to the northeast of the flight trajectory, which was evident as well by satellite observations of total ozone. Accompanying this transition were decreases in atmospheric pressure and temperature (Fig. 4, lower panels). Because the curtains illustrated in the top part of Fig. 4 include a temporal component, we did not perform a direct comparison with reanalyses. Therefore, both the 06:00 and 12:00 UTC reanalysis output times were included for comparison with the dropsonde measurements in the bottom half of Fig. 4. With respect to the lower panels, they show that the reanalyses compare well in recreating the position and strength of the jet. The center of the vortex is not represented as well, with the reanalyses having wind speeds that are too high and wind directions that are more northerly than the measurements indicate. However, we note that these errors are relatively small (wind speed error $\sim 5 \mathrm{~m} \mathrm{~s}^{-1}$; direction error $<15^{\circ}$ ).

The vortex strength, or the degree to which the cold vortex air is confined and mixing of outside air is minimized, creates conditions for a persistent environment where the 


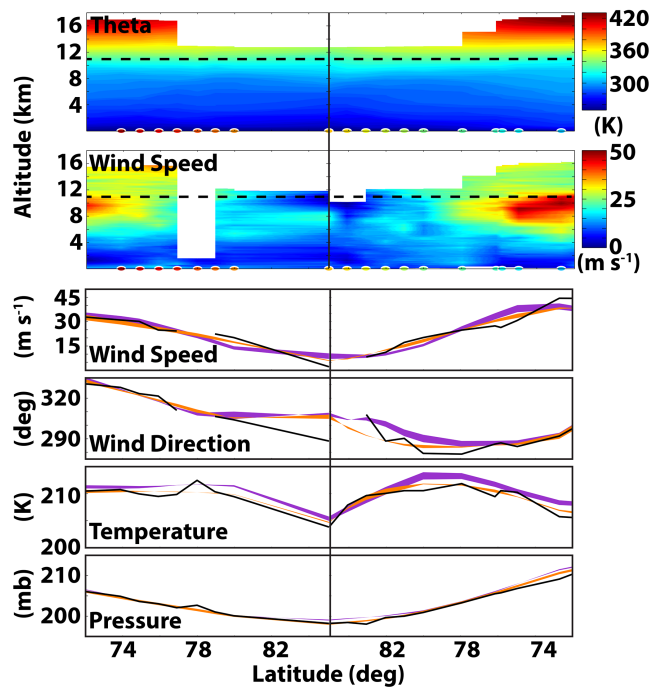

Figure 4. Top panels: potential temperature $(\mathrm{K})$ and wind speed $\left(\mathrm{m} \mathrm{s}^{-1}\right)$ cross sections on 10 March 2011. Colored dots represent dropsonde locations as depicted in Fig. 3. Lower panels, from top to bottom: wind speed $\left(\mathrm{m} \mathrm{s}^{-1}\right)$, wind direction (deg), temperature $(\mathrm{K})$, and pressure $(\mathrm{mb})$ at $11 \mathrm{~km} \mathrm{~m}$ a.s.l. (dashed line in top cross section) as measured by the dropsondes (black solid lines) and depicted in the ERA-I (orange) and R-2 (purple) reanalyses at 06:00 and 12:00 UTC (shading indicates range between times). Reanalysis data are interpolated to the $11 \mathrm{~km}$ height. The vertical black line in all panels corresponds to the northernmost dropsonde in Fig. 3.

chemical reactions that activate chlorine and destroy ozone exist (Manney et al., 2011). Dropsondes have also been used to capture details of the polar vortex in Antarctica from the Concordiasi experiment in 2010 (Wang et al., 2013). The Global Hawk dropsonde measurements illustrate that high altitude flight tracks, designed to characterize the position and gradients of the lower vortex, can provide information on vortex strength and persistence.

\subsection{Sampling of Arctic surface and boundary layer}

UAS and dropsonde technology can provide much needed information for understanding Arctic sea ice, ocean, and atmospheric systems; processes governing energy exchange among them; and processes impacting the location and movement of sea ice. To first order, sea ice movement is determined by near-surface winds and wind stress. These parameters are largely controlled by synoptic and mesoscale features, such as fronts and low-level jets, which can be modulated by the boundary layer thermal structure. However, techniques for estimating these parameters from large-scale model representations of the boundary layer have shown low correlations with actual ice motion (e.g., Thorndike and Colony, 1982) and poor comparisons to observed boundary layer structure and surface fluxes (e.g., Tjernström et al., 2005). The structure of these features and processes modulating them are particularly poorly understood and modeled

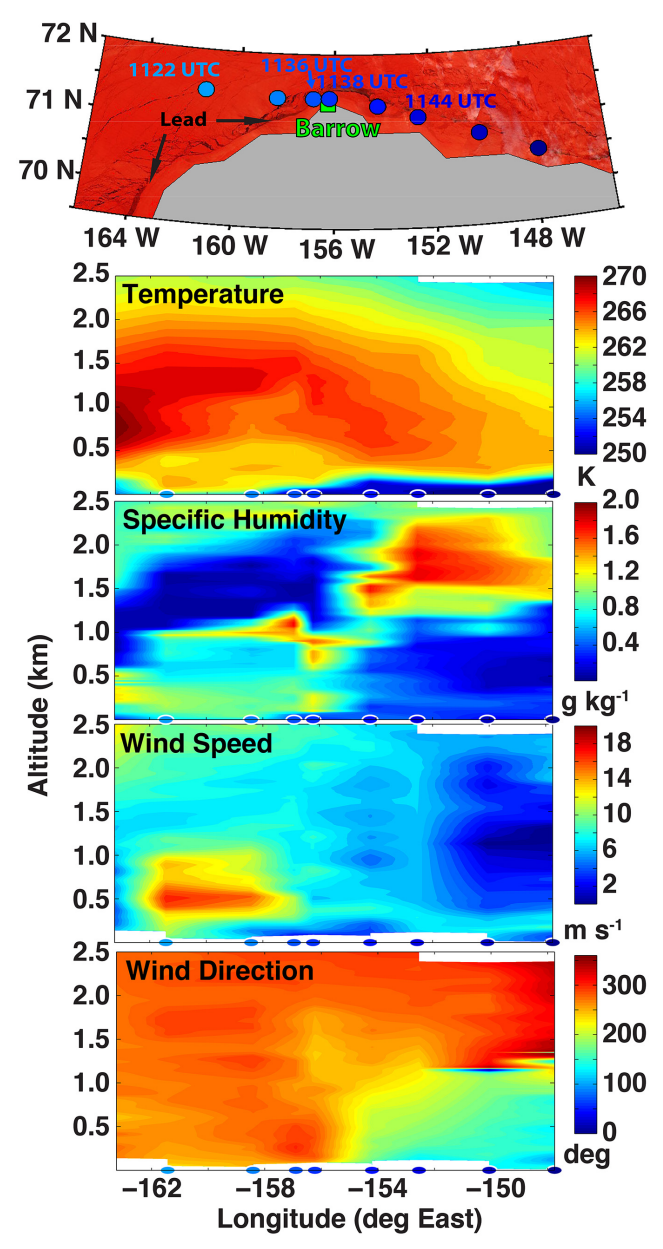

Figure 5. Upper panel: Global Hawk flight track on 10 March 2011 along Alaska's north coast (see Figs. 2 and 3 for larger-scale context), with dropsonde locations and times (UTC) overlaid onto a MODIS satellite image (overpass time, 10:30 UTC). Bands used for the image are band $3(459-479 \mathrm{~nm})$, band $6(1628-1652 \mathrm{~nm})$, and band $7(2105-2155 \mathrm{~nm})$; resolution is $500 \mathrm{~m}$. Lower panels, from top to bottom: dropsonde cross sections of (a) temperature (K), (b) specific humidity $\left(\mathrm{g} \mathrm{kg}^{-1}\right)$, (c) wind speed $\left(\mathrm{m} \mathrm{s}^{-1}\right)$, and (d) wind direction (deg). Dropsonde locations are marked with blue dots, as in the top panel, and match the colors used in Fig. 3.

over sea ice and in the marginal ice zone where spatially and temporally complex boundary layer structures occur. Dropsonde data can provide the vertically resolved boundary layer information needed to improve this understanding, ultimately resulting in improved atmospheric and sea ice forecasts.

An example of the detail offered by dropsondes is shown in Fig. 5, which documents a longitudinal transect just north of the Alaskan coastline. This transect passed over a sizable lead to the west of Barrow, as observed by the Moderate Resolution Imaging Spectroradiometer (MODIS). The "red" image is a composite of bands 3,6 , and $7(479 ; 1652 ; 2155 \mathrm{~nm})$ that best reveals snow and ice, which are reflective in the 


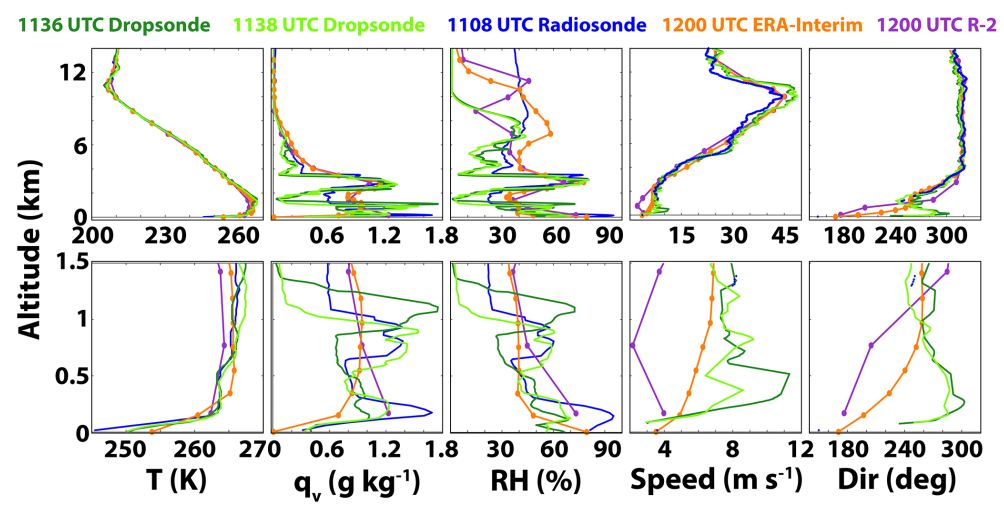

Figure 6. Plot of the Barrow Weather Forecast Office radiosonde launched (blue line) at 11:08 UTC on 10 March 2011, the Global Hawk dropsondes (green lines) at 11:36 and 11:38 UTC 10 March 2011, and ERA-I (orange) and R-2 (purple) reanalysis profiles (12:00 UTC 10 March 2011) interpolated in space to the averaged dropsonde location for the entire profile depth (top) and lower atmosphere (bottom). Included are (from left to right) temperature $(\mathrm{K})$, specific humidity $\left(\mathrm{g} \mathrm{kg}^{-1}\right)$, relative humidity $(\%)$, wind speed ( $\left.\mathrm{m} \mathrm{s}^{-1}\right)$, and wind direction (deg).

visible part of the spectrum (band 3) and highly absorbent in the shortwave IR (bands 6 and 7) - the water exposed in the lead feature appears dark since it absorbs in the red.

During this time, westerly flow associated with the largerscale polar vortex impinged on Barrow. Below $1 \mathrm{~km}$, a lowlevel jet, reaching speeds of $16 \mathrm{~m} \mathrm{~s}^{-1}$, contributed to a particularly warm and moist boundary layer. Also, directly above the lead at $156^{\circ} \mathrm{W}(11: 38 \mathrm{UTC} 10$ March 2011), a plume of moisture was observed, extending $400 \mathrm{~m}$ or more into the atmosphere. To the east of Barrow this westerly flow rode over a shallow, colder, and drier continental air mass moving in from the south-southwest, leading to substantially cooler surface temperatures and enhanced near-surface stability. The high resolution and spatial density of these dropsonde observations reveals several small-scale and subtle features in the temperature, wind, and humidity fields, highlighting the potentially important role this type of data could play in improving weather and ice forecasting and process study models.

Near the Barrow area, data from the 11:36 and 11:38 UTC Global Hawk dropsondes are compared with a contemporaneous upward radio sounding from the Barrow Weather Forecast Office launched at 11:08 UTC (Fig. 6). This upward sonde was at $\sim 8 \mathrm{~km}$ altitude at 11:38 UTC. There is very good correspondence among the sondes in the basic structure of the temperature profile, including features such as the inversion below $\sim 200 \mathrm{~m}$. There are small differences in magnitude at low levels and near the tropopause $(\sim 11-11.5 \mathrm{~km})$ most likely due to spatial differences between the radiosonde and dropsonde profiles.

The specific and relative humidity profiles, however, do not compare as well, which is partially due to their large variability both spatially and temporally. We speculate that the Barrow sounding is too humid in the upper troposphere and stratosphere $(40 \% \mathrm{RH})$ and values compare poorly at low humidities. This bias is potentially a result of poor performance of the carbon hygristor used in the VIZ-B2 radiosonde launched at Barrow (Wang et al., 2003). We note that on about 30 August 2012 the Barrow site switched from the VIZ-B2 radiosonde to Vaisala RS92, which is expected to perform much better in cold and dry conditions and has the same sensors as the dropsonde. In lower, moister layers, the dropsondes and radiosonde compare reasonably well in height and magnitude although some differences exist, which we postulate may be due to spatial inhomogeneity near the surface. As with the temperatures described above, the overall vertical structure of the wind speed and direction compare well between the mini-dropsondes and the Barrow sounding above the boundary layer. However, substantial differences in the wind observations are evident below around $2 \mathrm{~km}$, where even modest spatial differences of the profiles can be affected by coastal influences, low-level jets, and leads.

\subsection{Evaluation of reanalyses}

Atmospheric reanalysis data sets are commonly used to better understand atmospheric phenomena, provide forcing information for model experiments, and validate model results. Their utility has been hampered in the Arctic due to our inability to guide and subsequently validate these products. This inability to evaluate reanalyses is due in part to limited independent data set availability. Here, we demonstrate a potentially important role for Global Hawk observations by comparing dropsonde measurements to reanalyses produced by the European Centre for Medium-Range Weather Forecasting (ECMWF) and National Centers for Environmental Prediction (NCEP). Included in this evaluation are the ERA-Interim (European Reanalysis, hereafter ERAI) and NCEP-Department of Energy (DOE) (hereafter R-2) reanalyses. ERA-I (Dee et al., 2011) provides global analyses of atmospheric and surface state variables every $6 \mathrm{~h}$ from 

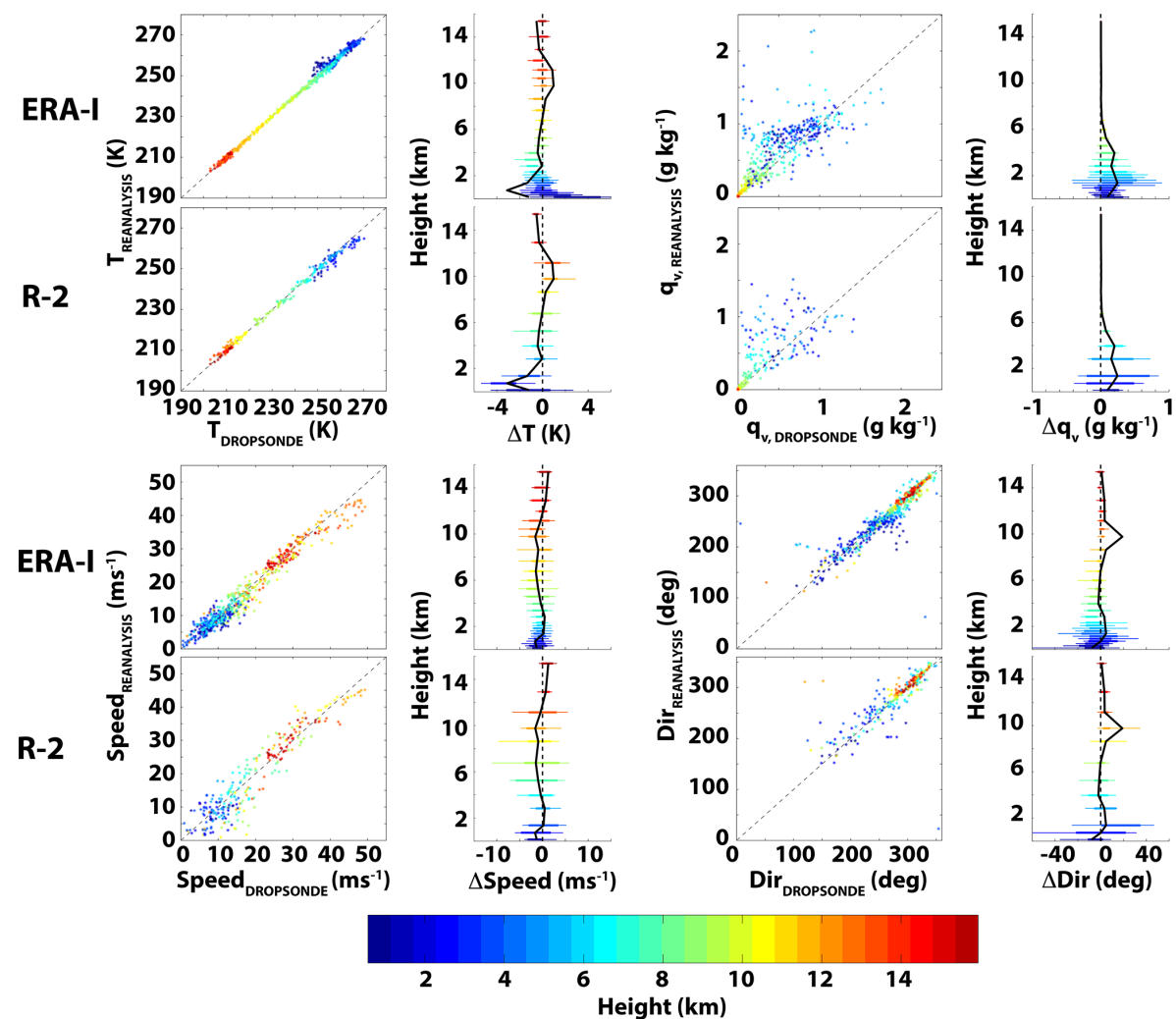

Figure 7. Comparison plots of ERA-Interim and R-2 reanalyses fields with dropsonde data for (clockwise from top left) temperature (K), specific humidity $\left(\mathrm{g} \mathrm{kg}^{-1}\right)$, wind direction $(\mathrm{deg})$, and wind speed $\left(\mathrm{m} \mathrm{s}^{-1}\right)$. Included are scatterplots comparing the dropsonde and reanalyses directly, as well as profiles of error distributions. The difference distributions represent the difference between the reanalysis estimate at the time closest to dropsonde deployment and the dropsonde measurement interpolated to the reanalysis heights (reanalysis minus dropsonde). The difference profiles include the mean (circle), 25th/75th percentiles (bars), and 10th/90th percentiles (whiskers) at each level. Color coding corresponds to altitude in kilometers (see color scale on the right).

1989 to present. ERA-I extends the capabilities of older products (ERA-15 and ERA-40) by utilizing an increased number of vertical levels (27) and higher horizontal resolution (T255, $\sim 0.7^{\circ}$ horizontal resolution, 11 grid points in the lowest $3 \mathrm{~km}$ ) and implementing advanced data assimilation techniques (4D-Variational) and model parameterizations. R2 (Kanamitsu et al., 2002) utilizes the same spatial (T62, 28 levels, $\sim 1.9^{\circ}$ horizontal resolution, and 4 grid points in the lowest $3 \mathrm{~km}$ ) and temporal (6 hourly) resolution as its predecessor (NCEP/NCAR, or R-1) and uses a 3-D variational assimilation technique. R-2 features advances in the handling of snow cover, humidity diffusion, relative humidity and oceanic albedo, amongst other things, when compared to R-1.

Despite having only one day of Global Hawk dropsonde profiles, some interesting features are noted through comparison of these data with reanalysis products. To facilitate the comparison, 06:00 and 12:00 UTC analyses from ERA-I and R-2 were interpolated linearly in space to the locations of dropsonde deployment. Dropsonde profiles were additionally interpolated linearly in space to heights matching those available in the reanalyses. Linear interpolation was deemed to be appropriate due to the limited variability in the evaluated variables between adjacent reanalysis grid boxes and the high resolution available from the dropsonde measurements. Comparisons were subsequently carried out between the dropsonde measurements and the interpolated reanalysis profiles using the analysis time closest to the dropsonde launch time (as shown in Figs. 4, 6, and 7). Additionally in Fig. 7, profiles of distributions of differences between the reanalysis estimates and dropsonde measurements (reanalysis minus dropsonde) for each quantity are illustrated. The difference profiles include the mean (circle), 25th/75th percentiles (bars), and 10th/90th percentiles (whiskers) at each level, with color coding representing the altitude in kilometers. For this particular day, ERA-I has a warm bias at the lowest atmospheric levels (surface to $500 \mathrm{~m}$ ) relative to dropsondes, while R-2 demonstrates a cold bias (Fig. 6, bottom row). Both reanalyses were too moist in the lower atmosphere, with significant scatter, and both had winds that were slightly too weak, particularly in the middle of the profile (6-10 km). 
While the spatial resolution of the reanalysis products is much coarser than that of the dropsondes, the biases observed do not necessarily appear to be linked directly to this discrepancy. ERA-Interim appears to have sufficient vertical resolution to resolve some of the major features observed in the radiosonde and dropsonde profiles, yet it fails to do so. The low resolution of the $\mathrm{R}-2$ product could be to blame for some of the biases detected for the lower atmosphere, given that the limited number of data points available vertically for the lowest $1.5 \mathrm{~km}$ do not allow that model to resolve some of the major features observed.

One striking feature that is readily apparent in the reanalysis evaluation is that differences are relatively smaller at higher altitudes, suggesting that the large-scale structure is well represented. For example, ERA-I captures the upperlevel, large-scale structure associated with the polar vortex (the range between 06:00 and 12:00 UTC output is shaded in the lower panels of Fig. 4). In more general terms (Fig. 7), upper-level wind speed and direction observations are well represented by the reanalyses, with mean errors generally less than $3-4 \mathrm{~m} \mathrm{~s}^{-1}$ and $5^{\circ}$, respectively. R-2 shows slightly larger error variability than ERA-I, particularly between 8 and $10 \mathrm{~km}$ above the surface. Upper-level temperature errors are typically less than $1 \mathrm{~K}$, with R-2 again showing slightly larger errors in the $8-10 \mathrm{~km}$ range. For specific humidity, what appear to be small errors at higher elevations are actually quite large on a percentage basis, which becomes more obvious when plotted as relative humidity (not shown in Fig. 7). An example comparison of individual dropsondes over Barrow (Fig. 6) shows this dramatic difference in relative humidity above about $4 \mathrm{~km}$, with reanalysis errors on the order of $20-40 \%$ and the largest errors occurring around $10 \mathrm{~km}$, which may be due, in part, to the moist bias in the Barrow radiosonde data that are assimilated by the reanalyses.

Relative to upper levels, somewhat larger reanalysis deficiencies are revealed at lower levels. These are related to inaccuracies in representing the Arctic inversion, the nearsurface boundary layer environment, and the actual surface state. Both biases are on the order of $2-4 \mathrm{~K}$. A look at individual profiles, such as those in Fig. 6, suggests that these low-altitude errors are the result of the misrepresentation of low-level jets and the near-surface environment in the reanalyses - specifically, the near-surface stability with R-1 being too stable and the near-surface (surface to $1 \mathrm{~km}$ ) stability with ERA-I not being stable enough. Wind direction errors show elevated variability near the surface, while both reanalyses are biased towards weaker, more southerly, winds below $1 \mathrm{~km}$ compared to the dropsondes. These wind biases could impact momentum transfer to the sea ice below.

Specific humidity is by far the least well represented variable of those reviewed. The largest absolute specific humidity errors are found in the lower troposphere, and both reanalysis products demonstrate moist biases relative to observations (Fig. 7), primarily due to overestimates in clear air. In spite of this bias, the reanalyses still miss important features, such as the low-level moist layers observed over the lead near Barrow (Fig. 6). (Note on the handling of sea ice in reanalyses: for this date, ERA-Interim obtains sea ice concentration from the Operational Sea Surface Temperature and Sea Ice Analysis (OSTIA; Donlon et al., 2012), which uses satellite measurements to produce a sea surface temperature (SST) and sea ice concentration product at $1 / 20^{\circ}$ resolution. R-2, on the other hand, utilizes AMIP-II (Atmospheric Model Intercomparison Project) sea ice boundary conditions (Hurrell et al., 2008). This product is based on the monthly mean Hadley Centre Sea Ice and Sea Surface Temperature data set (HadISST) and the NOAA weekly optimum interpolation SST analysis. This product only provides monthly mean sea ice concentration data on a $1^{\circ}$ grid.)

Several factors may contribute to such disagreements in humidity. First, as a result of large spatial and temporal variability, the spatial (point vs. grid box) and temporal separations of dropsonde and reanalysis profiles may contribute to the detected discrepancies. Regardless, there are several important potential repercussions of humidity errors, including incorrect placement and production of clouds. Routine dropsonde information incorporated into reanalyses data sets would likely improve spurious or technically insufficient measurements from fields such as the RH.

\section{Discussion and summary}

The WISPAR 2011 Arctic flight was a landmark demonstration mission using the Global Hawk UAS. It constitutes the first successful deployment of a large number of dropsondes from a UAS at high latitudes. Additionally, the flight transect through an unusually cold polar vortex, notable for record Arctic ozone loss, demonstrates the range of atmospheric conditions under which the Global Hawk can operate. This paper offered select highlights and examples of the dropsonde data illustrating the utility of these measurements in capturing interesting and unique Arctic atmospheric characteristics such as the polar vortex, surface inversions, and low-level jets. Comparison of the detailed dropsonde measurements with reanalyses showed good correspondence between the two on temperature, wind speed, and direction but poor reanalyses performance in capturing the humidity. Additionally, some smaller-scale and near-surface features were poorly represented across all variables.

One of the most prospective capabilities that Arctic UASs and dropsondes have to offer is providing observations for quasi-real-time data assimilation into operational weather forecast models. There are numerous examples of how extra dropsonde observations improve the accuracy of forecasts for winter storms, hurricanes, etc. (e.g., Szunyugh et al., 2000; Cardinali, 2000). However, because of the dearth of highlatitude soundings, dropsondes could assist in the improvement of operational weather, marine, and sea ice forecasts on 
1- to 15-day timescales. Larger evaluation data sets will be needed to assess the total impact of these measurements on forecast parameters in and downstream of the Arctic.

Additionally, UAS dropsonde technology can have important applications in further clarifying Arctic atmospheric processes and their effects on sea ice and the ocean surface layer. In this regard, dropsondes capture small-scale information on properties, such as stable Arctic boundary layers, low-level jets, and moisture layers that are not available from reanalyses or satellite observations. We recommend making use of Arctic UAS missions to survey and document sea ice and atmospheric parameters in all seasons to support improved understanding of seasonally varying processes and for input into seasonal sea ice extent forecasts. Finally, future UAS flights would offer an excellent source of support for drifting ice stations and field campaigns aimed at understanding the processes governing the complex interplay between ice, ocean, and atmosphere in a changing Arctic region. Currently, planning is underway for an international Arctic drifting station that includes deployment of in situ and remote sensors for a full annual cycle (Multidisciplinary drifting Observatory for the Study of Arctic Climate (MOSAiC)). Such as effort would benefit greatly from concurrent UAS dropsonde capabilities.

Despite the potential for such measurements, there are also challenges to overcome. Primary obstacles in the routine deployment of a UAS like the Global Hawk include limits with respect to the airspace where UASs can be deployed, identifying the optimal locations where targeted observations should be obtained, and the cost associated with UAS missions. In order to justify future deployments, additional documentation of the benefits is necessary. One potential avenue for doing so is through the use of data-denial experiments, where data from the Global Hawk dropsonde system could be assimilated into an ensemble of forecasts and subsequently withheld from a different ensemble in order to evaluate the improvement of forecast skill when using these measurements. Data-denial experiments are best done with extended data sets with good spatial coverage, which, in and of itself, can be challenging for UAS deployments at high latitudes, due to potential airspace limitations across international borders.

Ultimately, information gained from more frequent Arctic Global Hawk deployments could be of great value to the atmospheric and sea ice research communities, and the results shown here begin to illustrate that potential. In conjunction with additional observational efforts, these measurements could help us to improve our understanding of a rapidly changing Arctic environment and result in improved skill for models across many scales.
Acknowledgements. The authors wish to thank the NASA and NOAA Global Hawk support team, particularly Phil Hall, Dave Fratello, and Chris Naftel; NCAR dropsonde engineering and data team; and Son Nghiem (NASA JPL) for the MODIS satellite imagery. Additionally, we would like to thank Stuart Hinson, William Blackmore, and Scot Loehrer for their help with the Barrow, Alaska radiosonde data. G. de Boer acknowledges support from the National Science Foundation (NSF ARC1203902) and US Department of Energy (DE-SC0008794). M. D. Shupe acknowledges the US Department of Energy (DE-SC0007005).

Edited by: A. Stoffelen

\section{References}

Cardinali, C.: An assessment of using dropsonde data in numerical weather prediction, Proc. Second CGC/WMO Workshop on the Impact of Various Observation Systems on Numerical Weather Prediction, Toulouse, France, World Meteorological Organization, World Weather Watch Tech. Rep. 19, 131-141, 2000.

Cohen, J., Screen, J. A., Furtado, J. C., Barlow, M., Whittleson, D., Coumou, D., Francis, J., Dethloff, K., Entekhabi, D., Overland, J., and Jones, J.: Recent Arctic amplification and extreme mid-latitude weather, Nat. Geosci., 7, 627-637, doi:10.1038/ngeo2234, 2014.

Dee, D. P., Uppala, S. M., Simmons, A. J., Berrisford, P., Poli, P., Kobayashi, S., Andrae, U., Balmaseda, M. A., Balsamo, G., Bauer, P., Bechtold, P., Beljaars, A. C. M., van de Berg, L., Bidlot, J., Bormann, N., Delsol, C., Dragani, R., Fuentes, M., Geer, A. J., Haimberger, L., Healy, S. B., Hersbach, H., Hólm, E. V., Isaksen, L., Kållberg, P., Köhler, M., Matricardi, M., McNally, A. P., Monge-Sanz, B. M., Morcrette, J.-J., Park, B.-K., Peubey, C., de Rosnay, P., Tavolato, C., Thépaut, J.-N., and Vitart, F.: The ERA-Interim reanalysis: configuration and performance of the data assimilation system, Q. J. Roy. Meteor. Soc., 137, 553-597, doi:10.1002/qj.776, 2011.

Donlon, C. J., Martin, M., Stark, J., Roberts-Jones, J., Fiedler, E., and Wimmer, W.: The Operational Sea Surface Temperature and Sea Ice Analysis (OSTIA) system, Remote Sens. Environ., 116, 140-158, 2012.

Hock, T. F. and Franklin, J. L.: The NCAR GPS dropwindsonde, B. Am. Meteorol. Soc., 80, 407-420, 1999.

Hurrell, J. W., Hack, J. J., Shea, D., Caron, J., and Rosinski, J.: A new sea surface temperature and sea ice boundary dataset for the Community Atmosphere Model, J. Climate, 21, 5145-5153, 2008.

Kanamitsu, M., Ebisuzaki, W., Woollen, J., Hnilo, J., Fiorino, M., and Potter, G.: NCEP-DOE AMIP- II Reanalysis (R-2), B. Am. Meteorol. Soc., 83, 1631-1643, 2002.

MacDonald, A. E.: A global profiling system for improved weather and climate prediction, B. Am. Meteorol. Soc., 86, 1747-1764, doi:10.1175/BAMS-86-12-1747, 2005.

Manney, G. L., Santee, M. L., Rex, M., Liveseu, N. J., Pitts, M. C., Veefkind, P., Nash, E. R., Wohltmann, I., Lehmann, R., Froidevaux, L., Poole, L. R., Schoeberl, M. R., Haffner, D. P., Davies, J., Dorokhov, V., Gernandt, Johnson, B., Kivi, R., Kyro, E., Larsen, N., Levelt, P. F., Makshtas, A., McElroy, C. T., Nakajima, H., Parrondo, M. C., Tarasick, D. W., von der Gathen, P., Walker, 
K. A., and Zinoviev, N. S.: Unprecedented Arctic Ozone loss in 2011, Nature, 478, 469-475, doi:10.1038/nature10556, 2011.

Naftel, J. C.: NASA Global Hawk: A new tool for Earth science research, NASA Tech. Rep. NASA/TM-2009-214647, 2009.

Nash, J., Oakley, T., Vömel, H., and Li, W.: WMO Intercomparisons of high quality radiosonde system, Yangjiang, China, 12 July-3 August 2010, WMO/TD-No. 1580, available at: http://www.wmo.int/pages/prog/www/IMOP/publications/ IOM-107_Yangjiang.pdf (last access: 21 November 2014), 2011.

Neiman, P. J., Wick, G. A., Moore, B. J., Ralph, F. M., Spackman, J. R., and Ward, B.: An airborne study of an atmospheric river over the subtropical Pacific during WISPAR: Dropsonde budgetbox diagnostics, and precipitation impacts in Hawaii and California, Mon. Weather Rev., 142, 3199-3223, 2014.

Ralph, F. M. and Dettinger, M. D.: Storms, floods and the science of atmospheric rivers, EOS T. Am. Geophys. Un., 92, 265-266, doi:10.1029/2011EO320001, 2011.

Stroeve, J. C., Serreze, M. C., Holland, M. M., Kay, J. E., Maslanik, J., and Barrett, A. P.: The Arctic's rapidly shrinking sea ice cover: A research synthesis, Climatic Change, 110, 1005-1027, doi:10.1007/s10584-011-0101-1, 2012.

Szunyogh, I., Toth, Z., Morss, R. E., Majumdar, S. J., Etherton, B. J., and Bishop, C. H.: The effect of targeted dropsonde observations during the 1999 winter storm reconnaissance program, Mon. Weather Rev., 128, 3520-3537, 2000.

Thorndike, A. S. and Colony, R.: Sea ice motion in response to geostrophic winds, J. Geophys. Res., 87, 5845-5852, doi:10.1029/JC087iC08p05845, 1982.
Tjernström, M., Zagar, M., Svensson, G., Cassano, J. J., Pfeifer, S., Rinke, A., Wyser, K., Dethloff, K., Jones, C., Semmler, T., and Shaw, M.: Modeling the Arctic boundary layer: An evaluation of six ARCMIP regional-scale models using data from the SHEBA project, Bound. Lay.-Meteorol., 117, 337-381, doi:10.1007/s10546-004-7954-z, 2005.

Vaisala: Vaisala Radiosonde RS91 data sheet, available at: http:// www.vaisala.com/VaisalaDocuments/BrochuresandDatasheets/ RS92SGP-Datasheet-B210358EN-F-LOW.pdf (last access: 21 November 2014), 2012.

Wang, J., Carlson, D. J., Parsons, D. B., Hock, T. F., Lauritsen, D., Cole, H. L., Beierle, K., and Chamberlain, E.: Performance of operational radiosonde humidity sensors in direct comparison with a chilled mirror dew-point hygrometer and its climate implication, Geophys. Res. Lett., 30, 1860, doi:10.1029/2003GL016985, 2003.

Wang, J., Zhang, L., Lin, P.-H., Bradford, M., Cole, H., Fox, J., Hock, T., Lauritsen, D., Loehrer, S., Martin, C., van Adel, J., Weng, C.-H., and Young, K.: Water vapor variability and comparisons in subtropical Pacific from T-PARC Driftsonde, COSMIC and reanalyses, J. Geophys. Res., 115, D21108, doi:10.1029/2010JD014494, 2010.

Wang, J., Hock, T., Cohn, S. A., Martin, C., Potts, N., Reale, T., Sun, B., and Tilley, F.: Unprecedented upper-air dropsonde observations over Antarctica from the 2010 Concordiasi Experiment: Validation of satellite-retrieved temperature profiles, Geophys. Res. Lett., 40, 1231-1236, doi:10.1002/grl.50246, 2013.

Wang, M. and Overland, J. E.: A sea ice free summer Arctic within 30 years-an update from CMIP5 models, Geophys. Res. Lett., 39, L18501, doi:10.1029/2012GL052868, 2012. 